\title{
Comentarios Histórico - Médicos a propósito de una retención de placenta
}

\author{
Dr. Fernando Sánchez Torres *
}

Como es bien sabido, el general Francisco de Paula Santander fue acusado de haber participado en la conspiración dirigida contra el Libertador Bolívar la noche del 25 de septiembre de 1828. Detenido por orden del general Rafael Urdaneta, a la sazón Secretario de Guerra y Marina, Santander fue indagatoriado por primera vez el 28 de septiembre. La parte inicial del interrogatorio, que es la que nos interesa, es del siguiente tenor:

"En veintiocho de septiembre el señor General y acompañado pasaron a la casa del Colegio de Ordenandos, donde se halla preso el señor General de División Francisco de Paula Santander, a quien recibió juramento, que hizo bajo su palabra de honor, ofreciendo decir verdad en lo que supiera y fuera preguntado.

Preguntado dónde estuvo y qué conducta observó la tarde y noche del veinticinco del corriente, dijo: que para mejor absolver esta pregunta debe tomar la cosa desde las tres de la tarde, a cuya hora vino a comer a su casa, habiendo estado toda la mañana, desde las nueve pagando algunas visitas, como al Provisor Rocha, las señoras Almeidas, las señoras Uricoecheas, las señoras Sánchez, las señoras Genoveva Ricaurte y familia, el doctor Viana, en donde le parece que dieron las dos de la tarde, y antes (de) entrar a su casa visitó a la familia de las señoritas Mendozas; que habiendo llegado a la pieza donde habita, le avisó la mujer Antonia, que le cuida la casa, que su hermana la señora Josefa Santander estaba muy mala y que pedía un poco de aceite de almendras y se lo mandó; que

Profesor Titular de la Universidad Nacional. Miembro Fundador de la Sociedad Colombiana de Historia de la Medicina. comió muy a la ligera y salió para la casa de dicha su hermana, en donde encontró todas las personas de la familia y a las señoras mujeres del doctor Casimiro Calvo y la del doctor Casimiro Joaquín Suárez, que estaban asistiendo a la enferma; que por la detención de las pares, estaba bien mala; que mandó buscar al doctor Merizalde, que vino, recetó no sabe qué remedios y se fue, anunciando que iba a casa del Rector de la Universidad a una Junta de Gobierno. Que el exponente permaneció en la casa, y como cerca de las cinco de la tarde, lastimado de oír los ayes de la enferma, salió a la puerta de la calle y alcanzó a ver fuera de su casa a la mujer del señor José Vásquez Pose y, dirigiéndose a ella, le contó el estado en que se hallaba su hermana; que ella le dijo que a una mujer se le había quitado con tal remedio, de que no se acuerda, y le supliqué que se llegara a casa de su hermana, para ver si se le aplicaba. Que en la puerta de la calle de dicha señora estaba parada una de sus niñas y se dirigió a ella, con cuyo motivo entró en la casa, en donde estuvo conversando con las señoras un gran rato; que luego salió y volvió a casa de dicha su hermana, que vive en la Calle de los Carneros; cerca de la oración, viendo que el mal se agravaba, mandó a buscar al doctor Merizalde con el señor Honorato Rodríguez, pariente político del señor José María Briceño, y que habiendo respondido dicho Merizalde que no venía porque no se atrevía a hacer la operación de extraer las pares, llamasen al doctor Cheyne; que entonces hizo buscar al doctor Arganil, que vino, vio a la enferma y escribió una receta; que el exponente la tomó y con una criada llamada Liberata se vino a salir por detrás de la iglesia de San Victorino, a la plazuela, a la botica de un francés que la tiene establecida debajo de 
la casa que fue de don José Antonio Ugarte; que entró, le leyó la receta y le dijo que la despachara inmediatamente; que le contestó que tres de las drogas que se pedían, y recuerda ahora que eran agua escabiosa y de melisa, no las había en su botica, ni creía que las hubiera en ninguna otra; que el exponente escribió esta misma razón al pie de la receta y la devolvió con la criada a su hermano político; que se quedó conversando con el francés, a quien apenas había saludado anteriormente, sobre el mayor o menor expendio de su establecimiento, y aun le preguntó si había oído hablar de la propuesta que había la casa de Laffite, acerca de amortizar la deuda extranjera, sobre lo cual el exponente le respondió que no había oído decir que fuera la casa de Laffite y que sobre esta materia conversaron dando tiempo a que la criada regresara con alguna otra receta; que al cabo de un rato, que no parecía, salió de la botica y por el mismo camino por donde había venido a ella volvió a la casa de su hermana, andando despacio porque prefería ir así a oír los quejidos de la enferma, pero que solo iba por la calle, es decir, que no iba acompañado por nadie; que llegó a la casa y la enferma acababa de arrojar las pares detenidas. Que se quedó allí conversando sobre partos, sobre la correspondencia entre el Ministro del Perú, Villa, y nuestro secretario de Estado y sobre fábricas de casas; estando en esta especie de tertulia, las ya nombradas mujeres del doctor Calvo y el doctor Suárez, su prima Juana Santander, la señora Manuela Ramírez, su hijo el doctor Ezequiel Rojas, que le dijo se iba al otro día para Hato Viejo y quizá a Tunja, que qué era lo que se le ofrecía; que estaban también el doctor Arganil y el Padre Fray Miguel González, de San Diego, a quien se había llamado por el peligro en que estaba la enferma y porque es su director espiritual; que, como a las nueve de la noche, según le parece, se retiraron para sus casas todos los mencionados, a excepción de la mujer del doctor Calvo, del padre González y el exponente, que resolvió quedarse a dormir allí, como otras veces lo había hecho, como que al efecto, y con motivo de estas agitaciones políticas, siempre había una cama preparada para cuando quisiese ocuparla, y en esta ocasión lo decidió a ello el estado de enfermedad de su hermana" (14, pp 14-16).

Como vemos, la declaración anterior gira alrededor del estado de salud de doña Josefa Santander y

En la transcripción de documentos históricos se ha conservado la ortografía original. N. del A.
Omaña, hermana del general Santander y a quien éste profesaba un especial afecto. Ella había contraído matrimonio en Bogotá con el coronel venezolano José María Briceño Méndez el 19 de julio de 1820, actuando como padrinos su hermano Francisco de Paula y doña Nicolasa Ibáñez (8, p 257).

Doña Josefa había tenido un parto el día de autos, asistida a domicilio, como era costumbre en la época, por comadronas o matronas, en su caso por las esposas de los doctores Casimiro Calvo y Casimiro Joaquín Suárez, ninguno de los dos médicos. Recordemos que José Celestino Mutis, en un informe a la Corona fechado el 3 de junio de 1801, decía:

"Mas urgente há sido en los tiempos anteriores la necesidad de Parteras instruidas. Destinadas al oficio por herencia; acreditadas por su virtud, y honestidad; pero incapaces de auxiliar los Partos trabajosos y difíciles, han contribuido á mantener el capricho de resistirse las Parturientes a los auxilios de la Cirugía (...)" (10)*.

La historiadora Pilar Moreno de Angel anota en su admirable biografía de Santander que doña Josefa "había dado a luz uno de sus hijos en un parto complicado y difícil y además retenía la placenta" (8, p 452). Dado que no existen documentos que registren la forma como transcurrió el nacimiento, hay que aceptar que la afirmación de la señora de Angel, en el sentido de que fue un parto difícil, es una simple conjetura. Seguramente el parto propiamente dicho no tuvo complicación alguna y todo se redujo a una "detención de las pares", es decir, de la placenta, circunstancia ésta que nos ha servido para adelantar la presente disquisición históricomédica.

Doña Josefa ya había dado a luz otros hijos, o, mejor otras hijas, pues de sus nueve vástagos los siete primeros fueron mujeres $(8, \mathrm{p} 257)$. Si suponemos que la primogénita nació en 1821, al año de casada, es probable que el parto de 1828 corresponda a la cuarta o a la quinta niña ( a Mercedes de las Angustias o a Betsabé de los Dolores). Cualquiera de las dos pudo ser si asociamos sus nombres con el mal rato que pasaron la parturienta, las asistentas, los médicos y los familiares, por culpa de la malhadada placenta. Todo induce a aceptar que fue la quinta, Betsabé de los Dolores: el general Santander en su declaración dejó entrever que el alumbramiento de la placenta se había acompañado de dolores insoportables, tanto que los ayes de la enferma lo empujaron a dejar presto su casa a la hora de la oración y a regresar, bien entrada la noche, andando despacio "porque prefería ir así a oír los quejidos de la enferma". El trayecto recorrido no fue largo, como 
que su hermana vivía en la Calle de los Carneros, actual Avenida Jiménez de Quesada entre carreras 7a. y 8a., y la botica a donde fue a buscar lo ordenado por el médico estaba situada cinco a seis cuadras al occidente (plazuelas de San victorino). Yo me inclino a creer, no obstante, que la niña que nació aquel 25 de septiembre fue Mercedes de las Angustias, ya que la víspera la Iglesia católica conmemoraba a Nuestra Señora de las Mercedes, y en aquellas calendas se tenía muy en cuenta el santoral cuando de bautizar se trataba.

A pedido de Santander acudió, en primera instancia, el doctor José Félix Merizalde quien "recetó no sabe qué remedios y se fue, anunciando que iba a la casa del Rector de la Universidad a una Junta de Gobierno". Al concluir la tarde y en vista de que "el mal se agravaba", el general mandó a buscar de nuevo a Merizalde, quien se negó a atender la llamada pues "no se atrevía a hacer la operación de extraer las pares", y que mejor llamaran al doctor Cheyne.

Quien así participó en el episodio que nos ocupa era uno de los más prestigiosos médicos con que contaba la capital del país. Merizalde nació en Santafé en 1787. Estudió medicina en San Bartolomé, habiendo sido discípulo de Vicente Gil de Tejada, sucesor éste del Padre Isla, que falleció en 1807. Cabe recordar que el Padre Miguel de Isla fue junto con Mutis, el autor del primer plan de estudios de medicina establecido entre nosotros, y aprobado por Real Cédula en 1801. Merizalde recibió su grado en 1810 (2, p 27); muy pronto conquistó la confianza de la sociedad santafereña, figurando como médico de muchos patricios de la independencia. En los años de la Reconquista, o del Terror, fue obligado a prestar sus servicios a las tropas realistas. En su calidad de Segundo ayudante de Cirugía Médica le fue encomendado tratar los temas obstétricos dentro del programa de actividades de la primera Academia de Medicina que hubo en nuestro territorio, fundada en 1817 por el doctor Pablo Fernández de la Reguera. Merizalde desarrolló el jueves 20 de febrero los siguientes títulos:

Parto, a qué se da este nombre.

Expulsión y extracción, qué sean.

Por su naturaleza, o por el modo con que se termina, cómo se llama el parto.

Por el tiempo Id.

Por el tiempo de preñez en que se verifica, cómo se divide.

Por qué se dice ser verdadero o falso.

Parto natural cuál sea.

Id. laborioso: contra natural. Ligero. Prematuro. De todo tiempo.

Tardío, o retardado. Falso, Verdadero.

Aborto a qué se llama.

El parto laborioso cómo se divide.

¿Es fácil determinar los límites del parto natural?
Cómo se efectúa el parto natural. Regularmente cuáles sean los que tarden en parir.

De parte de la madre, y del fetus qué cosas deben desearse para pronosticar favorablemente.

Qué cosas son las que comúnmente retardan el parto. Causas de los partos muy ligeros, y precauciones que debe haber (3, p 242).

Así las cosas, José Félix Merizalde no era un ignorante en cuestiones obstétricas, por lo menos teóricamente. Pero, ¿en qué fuentes abrevó? De seguro que en la del español José Ventura Pastor y en la del francés Andrés Levret, que fueron los autores que Mutis recomendó en su famoso plan de estudios.

Revisando el libro Preceptos generales sobre las operaciones de los partos, publicado en Madrid en 1789 por Don José Ventura Pastor (15), Cirujano del Hospital General de la Pasión, (Fig. 1) encontramos la siguiente nota bene, a manera de presentación del autor:

FIGURA 1

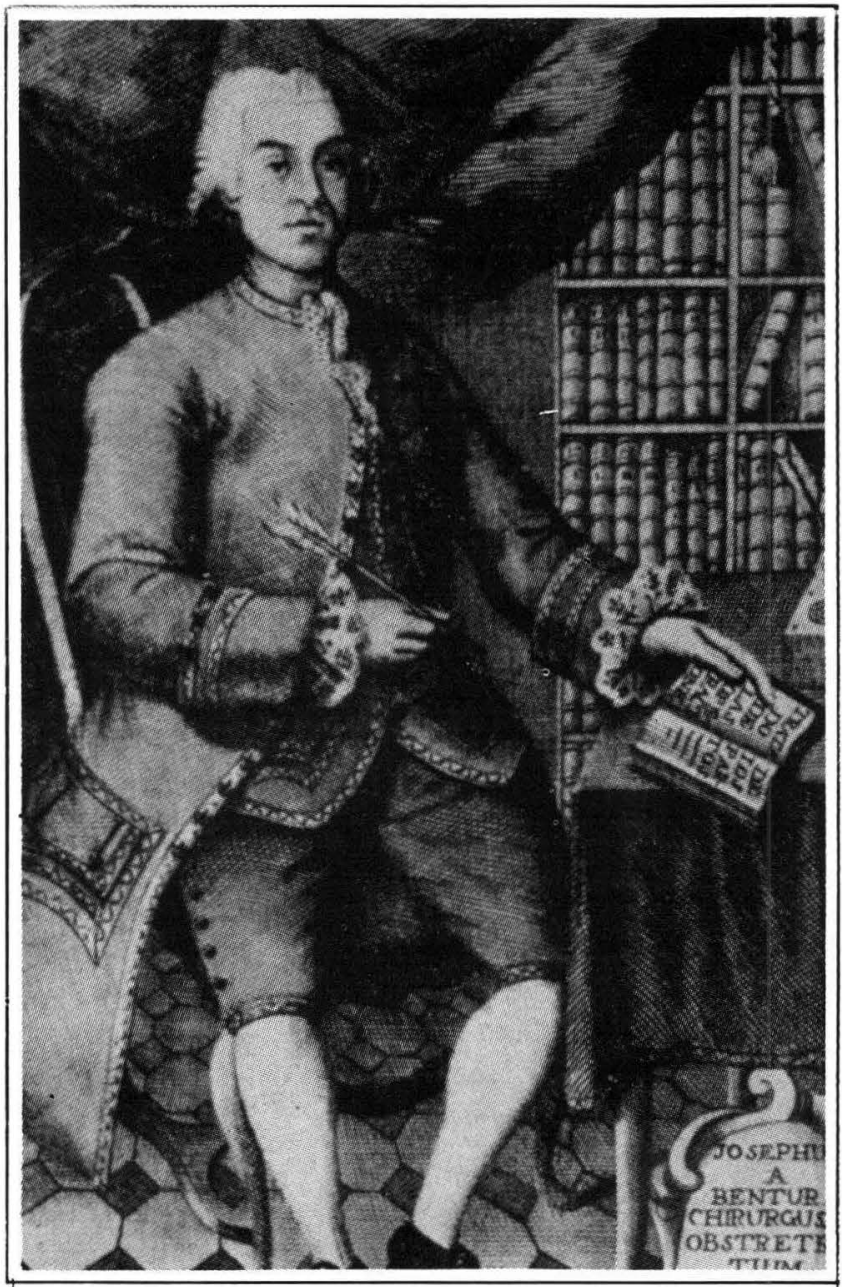

José Ventura Pastor, cirujano español, autor de Preceptos generales sobre las operaciones de los partos, obra recomendada por José Celestino Mutis en su Plan de Estudios de Medicina. 
“(...) no pretendo que nadie juzgue soy el primer escritor del arte obstetrice; pero también es cierto que lo más de todas sus partes, son producciones de la incesante práctica que he tenido en la época de 35 años, executando toda clase de las operaciones manuales que pueden ocurrir en esta parte de la Cirugia, y dirigiendo y curando todos los demás síntomas que contiene, unas veces solo, y otras acompañado de los Médicos más peritos de esta Corte, como lo justifican mis observaciones prácticas".

En relación con lo que nos interesa, Ventura Pastor le dedica un capítulo (el VIII) a la extracción de las secundinas, reseñando la forma como debe practicarse (pp 211-229). Si la maniobra que recomendaba no daba buenos resultados, se dedía proceder así:

“Mandará el asistente á la persona que esté más inmediata introduzca dos ó tres dedos en lo profundo de la boca de la parturiente, á fin de suscitarla el vomito, para que con el impulso y esfuerzo de él, se consiga su despresion y expulsion; si esto no basta, mandará á la misma persona aplique las manos sobre el vientre por encima de sus ropas ó vestidos, dará una mediana frotación en él, y por este medio se desprenderá la placenta y saldrá con prontitud".

Preconizaba también el español Ventura Pastor que si a pesar de estar desprendida la placenta no era posible extraerla mediante tracción del cordón, el cirujano "introducirá los dedos mayores de la mano derecha en el orificio del útero, teniendo con la izquierda asido el cordón umbilical, y con ello le dilatará lo suficiente hasta poder introducir toda la mano en su fondo, siguiendo la longitud del mismo cordón; y llegándola hasta la placenta, la tomará por su centro en la inserción del cordón, y la extraerá prontamente".

En caso de que el cirujano advirtiere que la placenta está muy adherida y para evitar la rotura del cordón o una inversión del útero, aconsejaba introducir la mano hasta el fondo y proceder a su desprendimiento. La maniobra es ilustrada con unas láminas o grabados muy graciosos.

De sospecharse la retención de alguna porción de las membranas enseñaba Ventura:

"Deberá no tomar mucha pena por esta detención, porque esta entraña procura exónerarse de ella al segundo ó tercero día por medio de algunos dolo-

Vale decir, el Sacramento de la Comunión o Eucaristía. N. del A. res expulsivos; solo procurará tener el vientre en una dulce transpiración por medio de algunos panos calientes, y para ayudar a la naturaleza á la deposición de este cuerpo extraño, y aplacar los dolores y la crispatura del utero; se le hará tomar media onza de aceyte de almendras dulces, sin fuego, en cada taza de caldo, ó en lugar de este tomará cada quatro horas una taza de agua de flor de malva, agregandola la misma cantidad de aceyte de almendras dulces, del xarabe de dialthea, ó el de culantrillo; y en el vientre se la subministrará una untura con los aceytes de azucenas, violado, ruda, azafran y manzanilla".

Entre las posibles circunstancias a que podría verse abocado el cirujano, Ventura Pastor trae la siguiente, que es necesario transcribir:

"P. Si el profesor fuese llamado para extraer una placenta con el cordon roto inmediato á su inserción mucho tiempo despues de haber nacido la criatura; ¿qué debe practicar?

R. En este caso debe observar; 1. si la paciente tiene ó ha tenido mucho dispendio de sangre, si se halla muy destituida de fuerzas, y si permanece aun con algunos desmayos y lipothimias; 2. si la placenta por su mucha detención se ha corrompido y suscitado calentura ú otro síntoma peligroso; 3 . observará é indagará si otro algun Cirujano ó Comadre á manejado á la paciente en el presente caso, y si las partes vaginales están maltratadas y heridas, á fin de sacar y dar su pronóstico á las personas interesadas y asistentes del peligro de la enferma, para que si muere despues de la operacion, quede en buen estado su reputacion; por lo que, en qualquiera de estos casos, despues de dado el pronostico, y antes de emprender la extraccion, debe aconsejarla se disponga para recibir el Veatico* por el grave peligro en que se halla (...)".

Finalmente, Ventura da el siguiente sabio consejo:

"Si prevee que usando de mayor violencia puede sobrevenir una inflamación del utero, y en su conseqüencia otros diferentes síntomas funestos que acostumbran subseguirse, es consejo de los prácticos se dexe la expulsion de la placenta, ó de sus porciones separadas á la obra beneficio de la naturaleza sino hay hemorragia copiosa de sangre ú otro síntoma que pueda hacer perecer á la paciente, ayudandola en este caso con los remedios externos é internos propios para corroborarla, y lacxantes para afloxar lo rígido de las fibras del cuerpo y cuello del utero: como son: alguna mixtura corroborante no hay incendiaria, los reparos de vino generoso, los caldos de substancia incorporando 
en cada taza media onza de aceyte de almendras dulces sin fuego, alguna lavativa lacxante un poco carminativa para que descargue los intestinos de algunos materiales estércorosos, y que suscite algunos conatos expulsivos, compuesta del cocimiento de manzanilla, matricaria y agrimonia, añadiendo un poco de cathalicon doble, y el aceite de ruda; ain olvidarse de las evacuaciones de sangre, según exiga la necesidad y fuerzas".

Hasta aquí las enseñanzas de Don José Ventura Pastor. Hemos tenido ocasión de revisar también tres obras de Andrés Levret que reposan en la Biblioteca Nacional: Essai sur l' abus des régles générales, et contre les préjugés qui s'opposent aux progres de l'art des accouchemens (4), Observations sur les causes et les accidens de plusieurs accouchemens laborieux (5) y Tratado de partos, demonstrado por principios de phisica y mecanica (6). En el primero, publicado en 1766 en París, dedica un capítulo (pp 170-189) a las causas de retención y técnica de la extracción de la placenta. En el tercero, publicado en Madrid en 1778. hace una mención muy corta del "enquistamiento de la

FIGURA 2

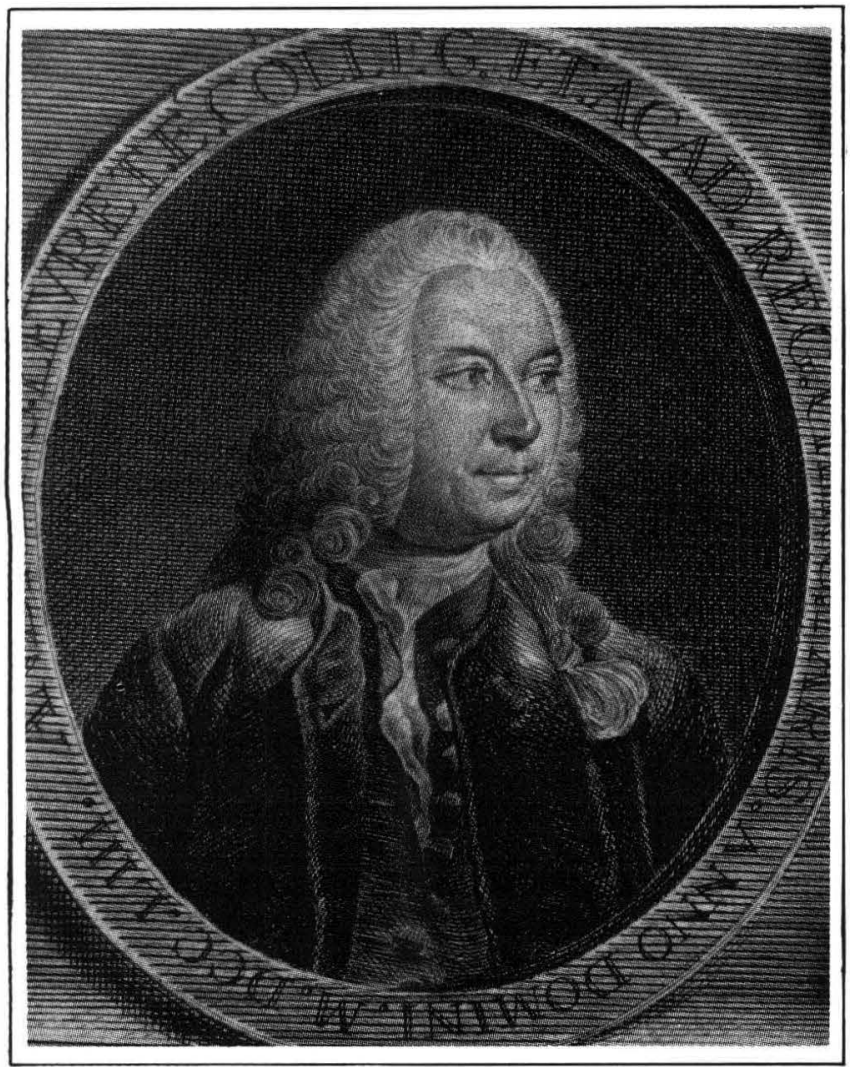

Andrés Levret, afamado cirujano francés del siglo XVIII. "Comadrón de Madama la Delfina”. Sus libros sobre partos los recomendó Mutis en 1801. placenta" y recomienda "introducir la mano, si se puede, en la cavidad uterina, y extraerla".

Andrés Levret fue un cirujano de renombre en París durante la segunda mitad del siglo XVIII, como que pertenecía al Colegio y Academia Real de Cirugía y tuvo el privilegio de ser "Comadrón de Madama la Delfina". (Fig. 2) No hay duda que fue maestro de José Ventura Pastor, pues éste hace referencia de aquél en algunos pasajes de su libro. Además, no hay mayor diferencia entre los consejos que el español daba para superar el problema de la retención de placenta y los que consigna en sus libros el francés.

Conocido el pensamiento de los autores recomendados por Mutis, ¿Se ciñó a sus enseñanzas José Félix Merizalde? Yo creo que sí: fue muy cauto y prudente, quizás por su experiencia, o por no ser cirujano. Ignoramos lo que prescribió en primera instancia. Seguramente provocar el vómito digitalmente o friccionar el abdomen. El aceite de almendras, tan mentado por Ventura, ya le había sido suministrado por iniciativa de las buenas señoras que asistían a doña Josefa. En vista de que pasaban las horas y las parias no se expulsaban, Merizalde no quiso comprometerse a practicar su extracción-pues estaba en juego su reputación-y recomendó, mejor que llamaran a Cheyne que era cirujano.

\section{Pero, ¿quién era Cheyne?}

Ninian Ricardo Cheyne era un cirujano escocés, de la Universidad de Glasgow, radicado en Colombia desde 1824. Como todos sus colegas de la época, estaba obligado a atender cualquier tipo de patología, incluyendo, por supuesto, la derivada del proceso del parto, más siendo tenido como cirujano. De ello dejó constancia José María Cordovez Moure en sus Reminiscencias de Santafé y Bogotá. Refiere el escritor costumbrista que

"Entre las muchas obras de caridad llevadas a cabo por el doctor Cheyne citaremos el caso de una mendiga que no podía dar a luz, e imploraba auxilio en un rancho levantado con desperdicios de la plaza de mercado, en las orillas del río San Francisco entre los puentes Nuevo y el Telégrafo. Al pasar cerca de allí el doctor, oyó las voces lastimeras y acudió al lugar de donde éstas salían: Impuesto el generoso médico de lo que se trataba, despachó al sirviente con el caballo y la orden de que le trajera los instrumentos adecuados a la operación indispensable para salvar la vida de aquella infeliz. Allí, en esa miserable vivienda, permaneció el sabio profesor hasta que sacó del trance a la madre y al hijo; compró personalmente, en una chichería inmediata, una taza de caldo que hizo 
tomar a la paciente, le dejó algunos reales de limosna, pagó a una mujer vecina con el fin de que cuidara a la enferma, se lavó las manos en el río y volvió a su casa al amanecer del día siguiente. La favorecida no fué ingrata y pregonó el beneficio recibido" $(1, \mathrm{p} 823)$.

¿Por qué se negó Santander a consultar al doctor Cheyne, si lo que se requería era un cirujano, tal como lo recomendaba el doctor Merizalde? No quedó de ello constancia, pero, quizás, intervinieron los hados protectores de doña Josefa. Es muy probable que si cheyne acude, procede, sin dilataciones, a extraer la placenta, exponiendo a la enferma al riesgo tan grande que eso significaba en una época en que no se tenían en cuenta ni la asepsia ni la antisepsia. El mismo cronista Cordovez Moure registra que

"El doctor Cheyne practicó con buen éxito operaciones dificilísimas y en extremo peligrosas sin tomar las precauciones que hoy se usan para prevenir la infección del paciente (...)" (1, p 822).

En la publicación que sus discípulos agradecidos hicieran en homenaje al connotado médico colombiano Antonio Vargas Reyes en 1851 -es decir, un poco más de veinte años después de ocurrido el asunto que nos ocupa- encontramos lo siguiente en relación con la retención de placenta:

"En todos estos casos los comadrones se apresuran a introducir la mano para estraer la placenta del seno mismo de la matriz o de sus dependencias, i la esperiencia ha demostrado que esta maniobra sumamente sencilla podrá no (?) tener las consecuencias funestas que diariamente se presentan en la práctica. ¡Ojalá nos fuera permitido citar los inumerables casos no solo de mujeres pobres sino de Señoras de distinción de esta ciudad, que han bajado a la tumba empujadas por estas maniobras imprudentes" (12).

Ante ese temor expreso, el profesor Vargas Reyes era enemigo de hacer una extracción manual prefería apelar a otros métodos. Recomendaba esperar de seis a ocho horas antes de emprender una conducta activa. De no haberse resuelto el problema espontáneamente, prescribía 25 gramos de ipecacuana, aprovechando su efecto emético. Se confiaba en que la contracción abdominal que acompaña al vómito fuera el factor que contribuyera a la expulsión de la placenta. De fracasar el procedimiento entonces aplicaba "agua fría aluminosa" por el cordón umbilical, o tópicos fríos en el abdomen (12).

¿Por qué, entonces, apeló Santander a los oficios del "doctor Arganil"? De seguro, por haberse sentido defraudado por Merizalde -como anota Martínez Zu- laica (7, p 209)-, y porque tenía una gran confianza en él como médico, tanta que había dado muestras de ser su protector. Repasemos quién era el "doctor Arganil".

Nadie sabe aún de dónde salió Juan Francisco Arganil. Al parecer de nacionalidad francesa, se apareció en Cartagena en 1822. Decía ser médico graduado en Montpellier, lo cual no pudo certificar él ni probar quienes se han interesado por indagar sobre su vida. No obstante, fue autorizado para ejercer pero, muy pronto, se le retiró la licencia ante el cúmulo de fracasos. En 1827 solicitó al libertador Bolívar permiso para ejercer en Bogotá, aspiración que se condicionó a los resultados de un examen practicado por un tribunal ad hoc, compuesto por los doctores Benito Osorio, José Félix Merizalde y Miguel Ibáñez (9, p 42). En el colmo de la sagacidad, Arganil resultó examinando a sus examinadores por medio de la prensa. El vicepresidente Santander nombró entonces un nuevo tribunal integrado por José Félix Merizalde, Domingo Sáiz y Domingo Arroyo. Cumplido el encargo, el tribunal dejó constancia de que "el citado Arganil era un ignorante de tiempo completo" (7, p 208). Sin embargo, Arganil continuó ejerciendo la medicina en forma velada, ya que solía ser consultado por personas prestantes de la sociedad. Alberto Miramón registra en su biografía de Arganil que era extraño su caso pues, habiendo sido descalificado por una junta de doctores y habiéndose prohibido a los boticarios de la ciudad despachar sus recetas, las gentes, especialmente las mujeres, acudían en busca de sus servicios $(9, \mathrm{p} 44)$.

De Merizalde decía Arganil que era un petulante; lo culpaba de la persecución de que había sido víctima. Podemos imaginar entonces la inmensa satisfacción suya cuando el vicepresidente de la República lo llama a atender a su hermana, luego que el profesor José Félix Merizalde se declarara incompetente para actuar. Arganil debió acudir presuroso al llamado. De seguro que no hizo reconocimiento médico alguno pues era lego en la materia. Por referencia de las matronas se informó del problema que afectaba a doña Josefa y procedió a poner a su servicio los conocimientos que poseía. Según el general Santander, "escribió una receta" que él mismo llevó a la botica de un francés, situada en la plazuela de San Victorino, y acompañado por la criada llamada Liberata. Al decir del boticario "tres de las drogas que se pedían no las había en su botica, ni creía que las hubiera en ninguna otra". Entonces el vicepresidente "escribió esta misma razón al pie de la receta y la devolvió con la criada a su hermano político".

Recuerda Santander que dos de las drogas prescritas eran agua escabiosa y agua de melisa. Revisando el listado de un poco más de medio centenar de aguas 
que figuran entre los medicamentos simples y compuestos autorizados para ser expendidos en las boticas de Santafé en 1799, no figuran las ordenadas por Arganil (3, p 265). Esto confirma, al parecer, que el boticario francés decía la verdad, pues puede pensarse que su negativa era consecuencia de la prohibición que el Gobierno había hecho, en 1827, en el sentido de que no se despacharan las recetas de Arganil.

Lo prescrito por el "doctor Arganil" probablemente no tenía ninguna relación con la complicación obstétrica. Melissa officinalis es el nombre técnico del "toronjil", al cual se le reconoce la virtud farmacológica de ser un tranquilizante de muy suave acción (13, p 139). En la lista de los medicamentos simples y compuestos mencionada atrás figura el "agua de torongil compuesta”, a 6 reales la onza. ¿Ignoraba el boticario francés que el agua de melisa fuera la misma agua de toronjil? En cuanto la escabiosa, es una planta herbácea, de la familia de las dipsacáceas, de cuya raíz se hacía un cocimiento que fue empleado en medicina; no nos fue posible conocer cuáles eran sus indicaciones. Quizás se le atribuyeran virtudes semejantes a las de la artemisa. Lo que es cierto es que Arganil actuó a la manera de los herbolarios de aquella época, como ese informador costeño que menciona José Celestino Mutis en su Diario de Observaciones. Se trataba de Gregorio del Pozo, quien refirió al mismo Mutis en Cartagena, en 1763, que en esa ciudad existía una yerba llamada Venadillo y otra llamada Artemisa, de buen efecto contra la dismenorrea y la retención de la placenta. "Yo las tengo experimentadas - decía el informador- en la retención de las pares después de haber parido, y en cuanto toman la dosis provocan las pares" (11, p 156). Como hecho curioso, el agua de artemisa sí figuraba en la lista de medicamentos autorizados en 1799; el precio era de medio real por onza (3,p 264).

En total de cuentas, parece que la participación de Arganil consistió apenas en hacer acto de presencia, a no ser que se hubiera atrevido a jalar del cordón umbilical para, con gran sorpresa de todos, extraer la placenta que ya se encontraba retenida en la vagina.
Cuando el general Santander, entrada la noche, regresó a la casa de su hermana, se encontró con la feliz noticia de que "la enferma acababa de arrojar las pares detenidas". Sin duda alguna, su admiración por Arganil debió acrecentarse. Este todavía se hallaba presente, acompañado del Padre Fray Miguel González, "a quien se había llamado por el peligro en que estaba la enferma y porque era su director espiritual".

Haciendo un recuento del episodio que hemos analizado puede concluirse que doña Josefa Santander de Briceño presentó una retención de placenta, debido quizás a un anillo de retracción en algún sitio de la cavidad uterina. Esta entidad, también llamada "encarcelación o engatillamiento placentario" ocasiona grandes dolores, pues el útero se contrae violenta e infructuosamente para expulsar el contenido. De ordinario no se acompaña de hemorragia. Una vez que cesa la retracción uterina la placenta, por gravedad, desciende y se deposita en la vagina. No se trata entonces de una verdadera retención por adherencia anormal, la cual no se acompaña de dolor pero sí de hemorragia. El problema en esta circunstancia no se resuelve espontáneamente, sino que obliga a la extracción manual, y algunas veces a procedimientos quirúrgicos más radicales.

Juzgando a los dos personajes que en función médica atendieron a doña Josefa, puede concluirse que actuaron prudentemente: Merizalde declarándose incompetente para intervenir y Arganil, sin declararse incapaz, manteniendo una actitud pasiva. Por fortuna para doña Josefa de Briceño, su hermano Francisco de Paula no llamó al cirujano Cheyne. De seguro que éste sí le practica la extracción manual, previa intervención de Fray Miguel González, según lo recomendaba el cirujano José Ventura Pastor, es decir, proporcionándole el Sacramento de la Eucaristía. La infección que quizás Cheyne hubiera sembrado en el útero de doña Josefa no le hubiera permitido a ésta dar a luz a sus otros cinco hijos, ni hubiera llegado a ser el apoyo moral y físico para su amado hermano durante sus muchas horas de dificultades.

BIBLIOGRAFIA

1. CORDOVEZ MOURE, J.M. Reminiscencias de Santafé y Bogotá. Ed. Aguilar, Madrid, 1957.

2. CUERVO, L.A. Noticias sobre la Historia de la Medicina en Santafé de Bogotá (1528-1938). Publicación de la Casa "Bayer", Bogotá, 1938.

3. HERNANDEZ DE ALBA, G. Contribución para la Historia de la Medicina en Colombia. Biblioteca Schering Corporation U.S.A., Bogotá, 1966.
4. LEVRET, A. Essai sur l'abus des régles générales, et contre les préjugés qui s'opposent aux progres de l'art des accouchemens. París, 1766.

5. LEVRET, A. Observations sur les causes et les accidens de plusieurs accouchemens laborieux, avec des remarques sur ce qui a été proposé ou mis en usage pou les terminer; et de noveaux moyen pour y parvenir plus aisément. Chez Delaguette, París, 1748. 
6. LEVRET, A. Tratado de partos, demosntrado por principios de phisica y mecánica. Imprenta de Pedro Marín, Madríd, 1778.

7. MARTINEZ ZULAICA, A. Cólicos Republicanos. Patobiografía del General F. de P. Santander. Imprenta de la Universidad Pedagógica y Tecnológica de Colombia, Tunja, 1978

8. MORENO DE ANGEL, P. Santander. Planeta Colombiana Editorial S.A., Bogotá, 1989.

9. MIRAMON, A, Tres Personajes Históricos: Arganil, Russi y Oyón. Plaza \& Janés, Editores, Bogotá. 1985.

10. MUTIS, J.C. Documentos sobre el mal estado de las ciencias en el Nuevo Reino. Sección Libros Raros y Curiosos, Biblioteca Nacional, Manuscrito No. 169, 1801.
11. MUTIS, J. C. Diario de Observaciones, tomo I. Instituto de Cultura Hispánica, Bogotá, 1983.

12. PEREIRA, P. Trabajos científicos del eminente médico granadino Dr. Antonio Vargas Reyes. Imprenta de la Nación Bogotá, 1859.

13. PIÑEROS, J.; GARCIA, H. y MONTAÑA, E. Extractos naturales de plantas medicinales. Fondo Editorial Universitario Escuela de Medicina Juan N. Corpas, Bogotá, 1988.

14. RODRIGUEZ PLATA, H. Santander en el exilio. Editorial Kelly, Bogotá, 1976.

15. VENTURA PASTOR, J. Preceptos generales sobre las operaciones de los partos. Madrid, 1789. 